\title{
SELF-REGULATED BEHAVIOUR AND MENTAL HEALTH AMONG IT
}

\section{PROFESSIONALS}

\section{CHINCHU. $\mathrm{C}^{1}$ \& KADHIRAVAN. $\mathrm{S}^{2}$}

${ }^{I}$ Research Scholar, Department of Psychology, Periyar University, Salem, Tamil Nadu, India

${ }^{2}$ Professor \& Head, Department of Psychology, Periyar University, Salem, Tamil Nadu, India

\begin{abstract}
Changes in the workplaces around the globe have placed many demands on individuals. Coping with such demands is of crucial importance to the wellbeing of employees, and eventually to organizational effectiveness. Self regulation can play an important role in ensuring positive mental health of employees. The present study explores the relationship between mental health and self-regulated behavior among IT professionals. Data was collected from a sample of 104 professionals working in the IT/ITES sector in various companies. Mental Health Continuum and SelfRegulated Behavior Scale were used for data collection. Results revealed a significant relationship between mental health and self-regulated behavior. Gender and marital status were also found to be associated with the two variables. Implications of the results are discussed.

KEYWORDS: Mental Health, Self-Regulated Behavior \& IT Professionals
\end{abstract}

Received: Jan 02, 2018; Accepted: Jan 22, 2018; Published: Jan 31, 2018; Paper Id.: IJHRMRFEB20184

\section{INTRODUCTION}

Workplaces of the present are unique in their own ways, with fast-changing facets of functioning and nature. Challenges are increasing and individuals in organizations are facing more demands from their workplaces and in personal lives. The environment in the modern workplace echoes what Lewis Carroll (1871) depicted, "it takes all the running you can do, to keep in the same place". Such an atmosphere is bound to create coping issues to an employee, and the personal psychological factors of individuals become crucial in deciding how each individual is capable of adjusting to the circumstances and performing optimally. The challenge for researchers in mental health is to identify factors that can help individuals lead better lives, despite the adversities.

\section{IT Professionals}

The IT/ITES industry is a good example of the stress-ridden modern workplace (Padma et al., 2015). Being a relatively new area of vocation, the long-term impacts of negative factors on mental health of IT professionals is not yet documented enough, even though it has been discussed widely in media and popular culture (Venugopal, 2010).The challenges faced by IT professionals are unique in many aspects. There are almost always deadlines to be met; one has to keep updating oneself in emerging technologies and platforms; timings at work may be odd, sometimes even threatening one's circadian rhythm. Stress at the workplace can have long-term detrimental effects on the overall lives of people(Kahn \& Dunnette, 1992). This can be harmful at two levels. At the individual level, as said above and at the organizational level, affecting the whole performance of the organization. 


\section{Mental Health}

One of the most important topics of inquiry in the realm of work, mental health is a crucial determinant of both personnel effectiveness and thereby organizational effectiveness. The definition and understanding of mental health has evolved over the years. From an illness orientation, the assessment of mental health has now taken a new course towards its positive aspects. A consensus has been arrived that mental health includes "subjective well-being, perceived selfefficacy, autonomy, competence, inter-generational dependence, and self-actualization of one's intellectual and emotional potential, among others" (World Health Organization, 2002). This understanding of mental health as a form of well-being, which also approaches the construct through one's actions in normal life puts the assessment and promotion of mental health on a plane similar to that of one's daily life. In other words, mental health is no longer an exclusive prerogative of the medical model, but more related to the normal life and its activities. Since work occupies a significant portion of a person's lifetime, research on mental health and well-being at workplaces is an important research requirement for the next decades. There have been notable suggestions that mental health research be linked to contextual factors for better effects (Briner, 2000).

\section{Self-Regulated Behaviour}

Self-regulated behaviour has been defined as "an active, constructive process whereby persons set goals for their work and then attempt to monitor, regulate and control their cognitions, emotions, motivation and action, guided and constrained by their goals and contextual features of the work environment" (Subramanian Kadhiravan \& Suresh, 2008). It is a multidimensional variable which covers important dimensions such as Self-Esteem, Self-Evaluation, Personal Control and Coping with Failure, among others. Viewed from the context of workplaces, it is a comprehensive measure of one's work-related performance abilities. Self-regulation is a key to shaping and mediating one's reactions to his/her changing environment (Pintrich \& Zusho, 2002).Thus an enquiry into the working of self-regulation can be a significant predictor of the workplace behaviour and well-being, and eventually the overall work outcome.

Stansfeld and Candy(2006) conducted an extensive meta-analytic review and concluded that effort-reward imbalances and the demand-decision latitude mismatch were potential risk factors in affecting the mental health of employees.Wang et al. (2008) conducted a population-based study on work stress and mental disorders and concluded that imbalances in the family-work equation can be better predictors of mental health issues, more than even stress at work. In a multi-country study, Llena-Nozal(2009) found that the type of employment is a significant factor in determining the mental health status of an employee, along with other factors. Roizen and Roach (2010) have advocated the implementation of targeted programs to improve the well-being of employees and thereby, overall productivity.

Wainwright and Calnan(2012)distinguished the two constructs of work stress and well-being in the context of work, and stressed on the need to combat work stress and promote well-being separately. Kitt and Howard(2013) have extrapolated the existing situation of occupational health research and demanded that "increased research is needed to explore the impact of a changing workforce and workplace" to cater to the needs of 2020 and beyond. Kyaw-Myint \& Strazdins (2015) have argued on the basis of their study among the industrial population that interventions for improving mental health aimed at individuals are easier to implement in organizations than higher level interventions like work redesign. 


\section{NEED FOR THE STUDY}

The changes that have been happening in the modern workplace are almost non-reversible due to economic and political reasons. The optimal solution is to enable the employees to cope up with the changing situations and keep themselves motivated and happy, along with performing their roles effectively. Aspinwall and Taylor(1997) have suggested that Self-regulation can lead to better proactive coping, which can be construed to a betterment in well-being. Self-Regulation has been linked to well-being in goal-directed processes (da Silva, Boivin, \& Gameiro, 2016) and this serves to show the crucial role that Self-regulation can play in the modern workplace management. Promotion of mental health and well-being are thus central to the functioning of any organization. It can reduce human costs and increase organizational outputs. With such a backdrop, it becomes crucial to explore the association between Self-regulation and mental health in the modern workplace within the cultural context of India.

\section{HYPOTHESES}

- Mental Health and Self-regulated behaviour of IT professionals are significantly related to each other.

- IT professionals differ in their mental health based on selected demographic variables.

- IT professionals differ in their self-regulated behaviour based on selected demographic variables.

\section{RESEARCH METHODS}

The study used survey method. The samples were drawn from IT professionals working in various companies via incidental sampling. Tools were distributed online to the participants, and continuous follow up was done to get the forms filled. A total of 104 data were considered for final analysis.

Mental Health Continuum by Keyes (2002): The short form of the Mental Health Continuum (MHC-SF) contains 14 items, answered on a 6-point Likert-type scale. It measures the dimensions of Emotional Well-being, Psychological Well-being and Social Well-being. It has demonstrated very good internal consistency $(>.80)$ as well as discriminant validity. Test-retest reliability has also been established.

Self-Regulated Behaviour Scale by Kadhiravan(2009): The scale is a 40-item measure, answered on a 5-point Likert scale. Eight dimensions of Self-Regulated Work Behaviour are assessed with this instrument. Validation procedures have established a split-half reliability of 0.792 , demonstrated intrinsic validity and content validity.

\section{RESULTS AND DISCUSSIONS}

Table 1: Relationship between Mental Health and

Self-Regulated Behaviour among IT Professionals

\begin{tabular}{|l|c|}
\hline Dimensions of Mental Health & Pearson' s 'r' \\
\hline Emotional Well-being & $.376^{*}$ \\
\hline Psychological Well-being & $.442^{*}$ \\
\hline Social Well-being & $.387^{*}$ \\
\hline Overall Mental Health & $.490^{*}$ \\
\hline
\end{tabular}

*-Significant at 0.05 level

Results in Table 1 indicate that all the three dimensions of mental health, and the overall mental health is correlated significantly with self-regulated behavior. Thus the first hypothesis stands accepted. There is indeed a positive 
relationship between mental health and self-regulated behaviour among the present sample.

Self-regulation is a process that integrates cognitions, emotions, motivations and action. It plays a mediatory role in the transactions that individuals make with their environment (Pintrich, 2000). Mental health is very much related to the way we perceive our environment, and the ways in which we react to the various facets of the environment, many of which are potential stressors too. Thus it can be construed that those with higher abilities for self-regulation are able to maintain higher levels of mental health and well-being.

Table 2: Difference in Mental Health among IT Professionals Based on Selected Demographic Variables

\begin{tabular}{|l|l|l|l|l|c|}
\hline \multicolumn{1}{|c|}{ Variable } & Category & $\mathbf{N}$ & Mean & SD & 't' value \\
\hline \multirow{2}{*}{ Gender } & Male & 88 & 40.42 & 14.22 & \multirow{2}{*}{$2.61^{*}$} \\
\cline { 2 - 5 } Marital Status & Female & 16 & 50.13 & 10.27 & \\
\cline { 1 - 5 } & Married & 39 & 46.77 & 12.33 & \multirow{2}{*}{$2.81^{*}$} \\
\cline { 2 - 5 } Age Group & Unmarried & 65 & 39.00 & 14.36 & \\
\cline { 1 - 5 } & Above 30 & 56 & 39.64 & 15.95 & \multirow{2}{*}{$1.79^{\mathrm{NS}}$} \\
\hline
\end{tabular}

*-Significant at 0.05 level; NS- Not Significant

A look at the results in Table 2 provides partial support to the second hypothesis. The table reveals that females are having significantly higher levels of mental health, when compared to males. In the case of common mental illnesses, women are generally found to be more vulnerable than men. However, positive aspect of mental health is a different concept and does not fall on the same spectrum as illness. The better mental health among females can be attributed to the fact that the work participation of women is generally very low in India, and having a white collar job may help women feel better about themselves, increase their self-esteem, and hence contribute to higher levels of mental health.

Married respondents are found to possess higher levels of mental health, as is seen among the general population.There is no significant difference in mental health between respondents aged below 30, considered 'youth'(Central Statistics Office, 2017) and those aged 30 and above. It can be concluded that age is not a significant factor as compared to others, in determining the mental health of IT professionals.

Table 3: Difference in Self-Regulated Behaviour among IT Professionals Based on Selected Demographic Variables

\begin{tabular}{|c|c|c|c|c|c|}
\hline Variable & Category & $\mathbf{N}$ & Mean & SD & 't' value \\
\hline \multirow{2}{*}{ Gender } & Male & 88 & 143.37 & 14.48 & \multirow{2}{*}{$2.94^{*}$} \\
\cline { 2 - 5 } & Female & 16 & 156.19 & 23.12 & \\
\hline \multirow{2}{*}{ Marital Status } & Married & 39 & 153.21 & 15.58 & \multirow{2}{*}{$4.01^{*}$} \\
\cline { 2 - 5 } & Unmarried & 65 & 140.62 & 15.51 & \\
\hline \multirow{2}{*}{ Age Group } & Upto 30 & 56 & 146.35 & 14.32 & \multirow{2}{*}{$0.67^{\text {NS }}$} \\
\cline { 2 - 5 } & Above 30 & 48 & 144.17 & 19.07 & \\
\hline
\end{tabular}

*-Significant at 0.05 level; NS- Not Significant

Results from Table 3 offer partial support to the third hypothesis as well. Female respondents are found to possess significantly higher levels of self-regulation, when compared to their male counterparts. This is keeping in line with the trend in the case of mental health, and corroborates the finding regarding the association between mental health and selfregulated behaviour. In the general population, tests of gender difference in self-regulation have yielded mixed results, with females having a slight advantage over males (Hosseini-Kamkar \& Morton, 2014). It has been suggested that women have an evolutionary advantage over men in employing self-regulation capabilities, and in a work atmosphere with a 
monotonous character, and lesser amount of novel challenges, women can be expected to fare better than men. Similar to the case of mental health, self-regulation is found to be higher among married respondents than the unmarried respondents. This is similar to the results obtained from elderly population reported from elsewhere (Fuladvandi et al., 2017), where married people were found to have higher levels of self-regulation when compared to the unmarried population. Age group is not found to be a significant discriminator between IT professionals in their self-regulated behaviour.

\section{CONCLUSIONS}

The study was an attempt at mapping the relationship between mental health and self-regulated behaviour among IT professionals, and also the important demographic factors that influence these variables. It has been found that mental health and self-regulated behavior are related to each other. This finding is relevant in the sphere of organizational development where measures to enhance organizational effectiveness should focus on strengthening the active and constructive processes that lead to better self-regulation and also on building a climate that promote psychological and social well-being of employees for the long-term benefit of the organizations.

\section{REFERENCES}

1. Aspinwall, L. G., \& Taylor, S. E. (1997). A stitch in time: Self-regulation and proactive coping. Psychological Bulletin, 121(3), 417-436. https://doi.org/10.1037/0033-2909.121.3.417

2. Briner, R. B. (2000).Relationships between work environments, psychological environments and psychological wellbeing. Occupational Medicine (Oxford, England), 50(5), 299-303.

3. Carroll, L. (1871). Through the Looking-glass. Auckland, New Zealand: Floating Press. Retrieved from http://www.gutenberg.org/files/12/12-h/12-h.htm

4. Central Statistics Office.(2017). Youth in India 2017 (p. 86). New Delhi: Ministry of Statistics and Programme Implementation, Government of $\quad$ Retrieved from http://mospi.nic.in/sites/default/files/publication_reports/Youth_in_India-2017.pdf

5. da Silva, S. M., Boivin, J., \& Gameiro, S. (2016). Self-Regulation and Wellbeing When Facing a Blocked Parenthood Goal: A Systematic Review and Meta-Analysis. PLoS ONE, 11(6). https://doi.org/10.1371/journal.pone.0157649

6. Fuladvandi, M., Safarpour, H., Malekyan, L., Moayedi, S., Mahani, M. A., \& Salimi, E. (2017). The Survey of Self-Regulation Behaviors and Related Factors in Elderly with Hypertension in South-East of Iran.Health, 09(04), 592-600. https://doi.org/10.4236/health.2017.94042

7. Hosseini-Kamkar, N., \& Morton, J. B. (2014). Sex differences in self-regulation: an evolutionary perspective. Frontiers in Neuroscience, 8. https://doi.org/10.3389/fnins.2014.00233

8. G. Swarupa Rani \& M. Sarada, Relationship between Mental Health and Wisdom of Retired Professionals, International Journal of Educational Science and Research (IJESR), Volume 7, Issue 5, September - October 2017, pp. 43-48

9. Kadhiravan, S. (2009).Developing a Measure of Self-regulated Work Behaviour.Journal of Psychological Researches, 53(2), $112-117$.

10. Kadhiravan, S., \& Suresh, V. (2008).Self-Regulated Behaviour at Work.Journal of the Indian Academy of Applied Psychology, 34, 126-131.

11. Kahn, R. L., \& Dunnette, M. D. (1992). Stress in organizations. In L. M. Hough (Ed.), Handbook of industrial and organizational psychology (Vol. 3, pp. 571-650). Palo Alto, CA: Consulting Psychologists Press. 
12. Keyes, C. L. M. (2002). The mental health continuum: From languishing to flourishing in life. Journal of Health and Social Behavior, 43(2), 207-222.

13. Kitt, M., \& Howard, J. (2013). THE FACE OF OCCUPATIONAL SAFETY AND HEALTH: 2020 AND BEYOND. Public Health Reports (1974-), 128(3), 138-139.

14. Taruna Malhotra, Influence of Family Environment on Mental Health of Students at Formal Operational Stage of Cognitive Development, International Journal of Environment, Ecology, Family and Urban Studies (IJEEFUS), Volume 6, Issue 2, March - April 2016, pp. 13-24

15. KYAW-MYINT, S. M., \& STRAZDINS, L. (2015).OCCUPATIONAL STRESS.In Health of People, Places and Planet (pp. 8194).ANU Press. Retrieved from http://www.jstor.org/stable/j.ctt1729vxt.18

16. Llena-Nozal, A. (2009). THE EFFECT OF WORK STATUS AND WORKING CONDITIONS ON MENTAL HEALTH IN FOUR OECD COUNTRIES.National Institute Economic Review, (209), 72-87.

17. Padma, V., Anand, N. N., Gurukul, S. M. G. S., Javid, S. M. A. S. M., Prasad, A., \& Arun, S. (2015). Health problems and stress in Information Technology and Business Process Outsourcing employees. Journal of Pharmacy \& Bioallied Sciences, 7(Suppl 1), S9-S13. https://doi.org/10.4103/0975-7406.155764

18. Pintrich, P. R. (2000). Chapter 14 - The Role of Goal Orientation in Self-Regulated Learning.In Handbook of Self-Regulation (pp. 451-502). San Diego: Academic Press. https://doi.org/10.1016/B978-012109890-2/50043-3

19. Pintrich, P. R., \& Zusho, A. (2002). Chapter 10 - The Development of Academic Self-Regulation: The Role of Cognitive and Motivational Factors. In A. Wigfield \& J. S. Eccles (Eds.), Development of Achievement Motivation (pp. 249-284). San Diego: Academic Press. https://doi.org/10.1016/B978-012750053-9/50012-7

20. Roizen, M. F., \& Roach, K. W. (2010).Wellbeing in the workplace.BMJ: British Medical Journal, 340(7757), 1150-1151.

21. Stansfeld, S., \& Candy, B. (2006).Psychosocial work environment and mental health a meta-analytic review.Scandinavian Journal of Work, Environment \& Health, 32(6), 443-462.

22. Venugopal, V. (2010, September 13). A big challenge for IT employees.The Hindu. Retrieved from http://www.thehindu.com/sci-tech/health/a-big-challenge-for-it-employees/article627693.ece

23. Wainwright, D., \& Calnan, M. (2012).The fall of work stress and the rise of wellbeing.In Work, health and wellbeing (pp. 161186).Policy Press at the University of Bristol. Retrieved from http://www.jstor.org/stable/j.ctt9qgksh.15

24. Wang, J. L., Lesage, A., Schmitz, N., \& Drapeau, A. (2008). The relationship between work stress and mental disorders in men and women: findings from a population-based study. Journal of Epidemiology and Community Health (1979-), 62(1), 42-47.

25. World Health Organization. (2002). The World Health Report: Mental health: new understanding, new hope (repr). Geneva: World Health Organization. 